\title{
Problems with the assessment of shame and guilt
}

\author{
Irina K. Makogon ${ }^{a}$, Sergey N. Enikolopov ${ }^{b}$ \\ ${ }^{a}$ Lomonosov Moscow State University, Moscow, Russia \\ ${ }^{b}$ Russian Academy of Medical Sciences, Moscow, Russia
}

\begin{abstract}
Moral emotions play a significant role in human behavior, and yet scholars are not unanimous in defining, differentiating, and measuring the basic moral experiences: shame and guilt. Because of this problem, the theory goes far beyond the empirical research on these emotions.

In this article we analyze the most widely accepted points of view on the difference between guilt and shame; those who espouse each point of view suggest their own assessment tools. Thus, one of the often-used methods, the Test of Self-Conscious Affect-3 (TOSCA-3) (Tangney, Dearing, Wagner, \& Gramzow, 2000), is based on a theory that differentiates shame and guilt according to where the negative evaluation of the misbehavior is aimed (at one's actions or at one's self). Another widely used questionnaire, the Dimensions of Conscience Questionnaire (DCQ) (Johnson et al., 1987), differentiates these emotions on the basis of whether the event causing them is public or personal.

The latest studies have shown that those methods are not contradictory. In addition, both the TOSCA-3 and the DCQ have their disadvantages; for example, they do not differentiate between emotional and behavioral aspects of guilt and shame. Thus, there is a need to develop a new assessment scale that overcomes these disadvantages. One such scale is the Guilt and Shame Proneness Scale (GASP) (Cohen, Wolf, Panter, \& Insko, 2011). The research conducted by its authors has established its reliability and validity, which allow us to consider the GASP as a progressive tool in assessing moral emotions, one that has great theoretical and practical value.
\end{abstract}

Keywords: shame, guilt, moral emotions, psychological assessment tools, TOSCA-3, GASP

Among human emotions there is a specific group of feelings that are connected with the way one sees one's self and one's actions as well as with one's self-concept in the sphere of social relations. In foreign writings such emotions are called selfconscious emotions, while Russian scholars call them social, meaning that there are other people within the context of the current emotional phenomena, or moral, meaning that they are the key feature of a person's morality and help draw a line between moral standards and moral behavior (Breslav, 2006). The feelings of shame and guilt occupy a central place in one's moral life. 
Shame and guilt develop naturally in the process of internalization-that is, the gradual transformation of one's (external) social-control mechanisms into one's own internal rules of behavior (Kon, 1979). Consequently, one of the most important functions of shame and guilt is to regulate (to deter) unethical and antisocial behavior (Tangney, Stuewig, \& Mashek, 2007).

Thus, the feeling of shame is crucial mainly because it helps one consider one's relations with others. The appearance of shame means these relations have gone wrong. The feeling of guilt, in its turn, regulates moral behavior: it makes one constantly analyze one's values and build one's life in accordance with moral standards to the maximum possible extent.

Shame and guilt make people sensitive to the feelings, attitudes, opinions, and assessments of those around them, and, consequently, they act as a force that brings people together. These emotions, according to Izard (1999), maintain conformity, encourage social responsibility, limit egocentrism and selfishness, and, thus, promote communication.

However, these emotions can transgress social adaptation and can complicate interpersonal communication when there is too much or not enough of them (Breslav, 2006; Potter-Efron, 2002).

Although scholars are unanimous in admitting that these two moral emotions are crucial for one's ethical and moral behavior, they disagree about how these emotions should be defined, differentiated, and measured (Cohen et al., 2011; Tangney, 1996; Tangney et al., 2007).

The first references to the significant role of the social emotions can be found as early as in Freud's work The Ego and the Id (1923). Freud regards the feeling of guilt as an indicator of internal conflict and the feeling of shame as a means of controlling sexual impulses, especially exhibitionism and voyeurism. The feelings of guilt and shame were further considered by Franz Alexander, and played a significant role in Erik Erikson's stages of development. Yet all the following works of psychoanalysis discussed various models only of the differentiation of shame and guilt, as well as the order of their appearance in one's development.

The first big symposium on emotions, held in 1928, did not even raise the question of social emotions, while the second symposium, held in 1948, presented two reports on the feelings of shame and guilt: one by an American psychiatrist, Richard L. Jenkins, who defined guilt as a feeling of self-discontent caused by the realization that there is a discrepancy between one's behavior and accepted moral standards and who stated that the purpose of guilt is to adjust one's behavior to moral standards; and the other study by a Belgian psychologist, Joseph Nuttin, who connected shame with a breach in the immunity of the inner world and of psychological intimacy (Breslav, 2006).

The Russian psychological school has also made attempts at describing and researching social emotions: the analysis of preschool children's feeling of shame as an indicator of their moral development, done by E.I. Kulchitskaya (1966); the work of V.L. Levi and L.Z. Volkov on shyness (1970); the analysis of empathy, done by T.P. Gavrilova (1974).

Since the turn of the century there has been a considerable increase in interest in self-conscious emotions among scholars; however when analyzing the papers, 
we mainly come across foreign works on the subject (including those by K.W. Fisher, J.P. Tangney, T.J. Ferguson, M.F. Mascolo and others).

Russian scholars refer to the phenomena of shame and guilt in reference to the common theory of emotions and feelings (J.I. Sidorenko, G.H. Shingarov, P.M. Jacobson), the theory of moral development and upbringing (V.A. Malakhov, S.G. Jacobson, V.G. Schur), the study of social adaptation (A.P. Rastigeev), or the research on self-consciousness and self-evaluation (I.S. Kon, S.R. Pantileev, I.N. Semenov, E.T. Sokolova, V.V. Stolin, and others) (Breslav, 2006).

Although the notions of shame and guilt have always appeared in various social-ethical theories and in psychopathology, the theory goes far beyond the empirical studies. The need for measurement-for a psychometric scale for shame and guilt-is the key factor that hampers empirical studies of these emotions (Nathanson, 1992). When analyzing the existing works, we face two problems: the problem of the present definitions of shame and guilt and the problem of how good these definitions are for examining the phenomena of guilt and shame.

For a long time scholars did not differentiate between shame and guilt; in many modern papers on clinical psychology these terms are used as synonyms. Indeed, they both are self-conscious emotions, evoked by self-reflection and self-evaluation; both are characterized by feelings of distress (Tangney et al., 2007), and both aid in self-regulation (Tangney, 1996; Tangney \& Dearing, 2002).

Despite the similarities there are important differences between these two emotions. Thus, for example, some comparative studies elicit the difference in the motivational consequences of shame and guilt: guilt brings forth positive preventive incentives, while shame elicits defensive interpersonal separation and detachment (Elison, Lennon, \& Pulos, 2006; Tangney, 1996).

Numerous clinical observations have shown that shame proneness, as opposed to guilt proneness, is connected with a wide range of psychosomatic symptoms, from low self-esteem, depression, and uneasiness to eating disorders, posttraumatic stress disorders, and suicidal tendencies.

Studies also reveal the different roles that shame and guilt play in risky and deviant behavior. It has been found that guilt negatively relates to antisocial and risky behavior, while shame positively correlates with intentions for illegal behavior (Guimon et.al., 2007). Shame and guilt also differ in their correlation with empathy. Guilt proneness correlates positively with charm and empathy, while shame, on the opposite side, is connected with obsession with one's own distress (Tangney, 1996).

The nature of these numerous differences is still a subject for scholarly debates.

Currently, there are two main points of view about the differences between shame and guilt.

First, a number of authors believe that guilt and shame can be differentiated via a self-behavior distinction (Lewis, 1971; Tangney, 1996). This theory provides that with guilt the focus is on one's own action, mental or physical ("I did a bad thing"), whereas with shame the focus is on one's self ("I'm a bad person"). In other words, guilt arises when one makes internal, specific attributions about one's actions; these attributions, in their turn, lead to negative feelings about a specific behavior that 
one has performed (Tracy \& Robins, 2004). Shame arises when one makes attributions about one's self; such attributions lead to negative feelings about the global self (Tracy \& Robins, 2004). Thus, shame is more painful than guilt and comprises the feelings of helplessness and worthlessness.

This theory has substantial empirical support, including experimental and correlation studies (Tangney, 1996; Tangney et al., 2007).

Moreover, the Test of Self-Conscious Affect-3 (TOSCA-3), the most widely used guilt- and shame-proneness assessment, relies on the self-behavior distinction (Tangney et al., 2000). Its first version was devised under the supervision of Tangney in 1989, at George Mason University (Tangney, Wagner, \& Gramzow, 1989). Currently, the test is adjusted for various ethnic groups and different ages (abroad there are variants of this test suitable for adults and for children and adolescents).

We have translated the TOSCA-3 and conducted it using the Russian material (Makogon \& Enikolopov, 2009). Our research has shown that the Russian version of the method can be considered a reliable and valid psychological-assessment tool.

The TOSCA-3 consists of 16 short stories of situations that people are likely to encounter in day-to-day living; they presuppose a rise of guilt, shame, or other moral emotions. Each situation is followed by descriptions of several emotional, cognitive, or behavioral reactions to the stories.

The task of those being tested is to indicate how likely they would be to react in each of the ways described, using the 5-grade Likert scale.

The scoring presupposes the use of 6 subscales:

1. Guilt proneness measures the guilt proneness of someone making a negative evaluation of one's behavior.

2. Shame proneness measures the shame proneness of one making a negative evaluation of the global self.

3. Externalization measures proneness to blaming other people or circumstances for the consequences of one's actions (proneness to an external locus of control).

4. Detachment/unconcern measures the degree of emotional involvement (or, to be more precise, noninvolvement) in the situation and its consequences.

5. Alpha pride measures proneness to a positive evaluation (pride) of one's self.

6. Beta pride measures proneness to pride in one's current behavior.

In the TOSCA-3, guilt responses are characterized by regret and negative behavior evaluations (e.g., thinking "I made a mistake"), as well as repair-action tendencies (e.g., apologizing). Shame responses are characterized by negative selfevaluations (e.g., thinking "I am a terrible person") and withdrawal-action tendencies (e.g., hiding).

The TOSCA-3 has the following advantages: (a) the evaluation of affective feelings is performed within the specific context; (b) the person being tested does not need to differentiate between the abstract notions of shame and guilt; (c) such 
an approach does not provoke defensive reactions. In addition, the stories in the TOSCA-3 are focused not on cognitive evaluations but on phenomenological descriptions of the experience; this focus rules out the possibility of evaluating moral standards instead of feeling specific moral emotions (Kugler \& Jones, 1992; Tangney, 1996).

However, other works reveal considerable disadvantages of Tangney's test. Shame and guilt are compound psychological phenomena: they consist of cognitive, emotional, and behavioral aspects. One limitation of the TOSCA-3 is that emotional and behavioral responses to transgressions are confounded: negative behavior evaluations and repair-action tendencies are not differentiated, and neither are negative self-evaluations and withdrawal-action tendencies. The latest research has shown that evaluative or emotional responses can be differentiated theoretically and empirically from behavioral responses (Wolf, Cohen, Panter, \& Insko, 2010). Theoretically, the difference can be conceptualized as the distinction between attitudes and intentions.

Empirically it has been found that people are more likely to react to transgressions with negative self-evaluations than with withdrawal-action tendencies (although both types reflect shame proneness in different ways) (Wolf, Cohen, Panter, \& Insko, 2010). Moreover, Schmader and Lickel (2006) found that shame can elicit repair behaviors as well as withdrawal behaviors and likewise for guilt. This research proves that the emotional responses (attitudes) of shame and guilt differ from withdrawal- and repair-behavior tendencies (intentions) and thus should be differentiated in related studies.

Second, an alternative point of view, which has its roots in anthropology (Benedict, 1946), takes the public-private distinction as a basis for the differentiation of guilt and shame. According to this approach, transgressions or failures that have not been publically exposed (private misdeeds) are likely to elicit feelings of guilt, whereas transgressions or failures that have been publicly exposed are likely to elicit feelings of shame. Therefore, guilt is associated with a private sense of having done something wrong or having behaved against one's conscience. Shame is the negative feeling that arises when one's failures and shortcomings are put on public display (Cohen et al., 2011).

The Dimensions of Conscience Questionnaire (DCQ) is based on the publicprivate distinction. In the DCQ, the guilt items ask respondents to indicate how badly they would feel after committing private transgressions (e.g., "secretly taking office supplies home for personal use"), and the shame items ask respondents to indicate how badly they would feel after committing public transgressions (e.g., "getting drunk and making a fool of yourself in public").

In a study guided by Wolf (Wolf et al., 2010) both the public-private and the self-behavior distinctions were experimentally tested, and it was proved that both have problems. For example, low self-esteem is a construct that is theoretically more closely linked to shame proneness than to guilt proneness (Tangney \& Dearing, 2002). But Wolf and his colleagues found that items describing negative self-evaluations following private transgressions were not correlated as strongly with low self-esteem as items describing negative self-evaluations following public 
transgressions. In addition, both the guilt and the shame scales of the TOSCA-3 and the DCQ correlated positively in spite of having different theoretical bases.

No existing scale measures guilt proneness and shame proneness using both the self-behavior and the public-private distinctions, nor does any existing measure differentiate emotional and behavioral responses. This is a problem because both distinctions have received empirical support, and emotional and behavioral responses to transgressions are conceptually and empirically different (Wolf et al., 2010). Therefore, current studies are aimed at developing new scales that overcome all the above-mentioned disadvantages. One of the proposed methods is the Guilt and Shame Proneness Scale (GASP) (Wolf et al., 2010).

The GASP is aimed at measuring emotional traits (i.e., guilt and shame proneness). This test is based on different situations that occur in day-to-day life and a person's possible reactions to those situations. As respondents read a description of each situation, they are asked to imagine themselves in that situation and to indicate how likely they would be to react in the way described. The GASP contains two guilt-proneness subscales, which assess negative behavior evaluations and repair responses to private transgressions or failures, and two shame-proneness subscales, which assess negative self-evaluations and withdrawal responses to publicly exposed transgressions or failures. Guilt-negative-behavior-evaluation items describe feeling bad about how one acted (e.g., "you would feel that the way you acted was pathetic"). Guilt-repair items describe action tendencies (i.e., behavior or behavioral intentions) focused on correcting or compensating for the transgression (e.g., "you would try to act more considerately toward your friends"). Shame-negative-self-evaluation items describe feeling bad about oneself (e.g., "you would feel like a bad person"). Shame-withdrawal items describe action tendencies focused on hiding or withdrawing from the public (e.g., "you would avoid the guests until they leave").

The research conducted by the authors of the GASP has proven its validity and reliability. The results confirm the hypothesis that it is important to differentiate between emotional and behavioral aspects of guilt and shame for a detailed understanding and assessment of these emotions. These data allow us to consider the GASP as a new, progressive method for measuring moral emotions, a method that has theoretical and practical value.

We have translated and tested the GASP on a Russian-language sample. The results prove the validity and reliability of the Russian version of the GASP in measuring guilt and shame proneness.

In this article we have analyzed the literature on moral emotions, which shows that the number of both theoretical and empirical studies of these important regulators of human behavior, such as guilt and shame, has significantly increased, but at this moment in Russia and abroad these phenomena have not been studied enough: many important questions still remain open. This situation points to the need for intensified research in the field of self-conscious emotions in general, and guilt and shame in particular, including the further development of the methodological arsenal. 


\section{References}

Benedict, R. (1946). The chrysanthemum and the sword. New York: Houghton Mifflin.

Breslav, G. M. (2006). Psyhologia emociy [Psychology of emotions]. Moscow: Smysl, Akademia.

Cohen, T. R., Wolf, S. T., Panter, A. T., \& Insko, C. A. (2011). Introducing the GASP Scale: A New Measure of Guilt and Shame Proneness. Journal of Personality and Social Psychology, 100(5), 947-966. doi: 10.1037/a0022641

Elison, J., Lennon, R., \& Pulos, S. (2006). Investigating the compass of shame: The development of the compass of shame scale. Social Behavior and Personality, 34, 221-238.

Freud, S. (2007). The Ego and the Id. Moscow: EKSMO.

Gavrilova, T. P. (1974). Experimentalnoe izuchenie empatii u detey mladshego i srednego shkolnogo vozrasta [Experimental study of empathy in children of primary and secondary school age]. Voprosy Psyhologii [Issues of Psychology], 5, 107-114.

Guimon J., Las Hayas C., Guillen V., Boyra A., \& Gonzalez-Pinto A. (2007). Shame, Sensitivity to Punishment and Psychiatric Disorders. Eur. J. Psychiat., 21(2), 124-133. doi: 10.4321/ S0213-61632007000200004

Izard, K. E. (1999). Psyhologia emociy [The psychology of emotions]. St. Petersburg: Piter.

Johnson, R. C., Danko, G. P., Huang, Y. H., Park, J. Y., Johnson, S. B., \& Nagoshi, C. T. (1987). Guilt, shame and adjustment in three cultures. Personality and Individual Differences, 8, 357-364. doi: 10.1016/0191-8869(87)90036-5

Kon, I. S. (1979). Moralnoe soznanie lichnosti i regulytivnye mehanizmy kultury [The moral conscience of the individual and the regulatory mechanisms of culture]. In M. I. Bobnevoy \& E. V. Shorohovoy (Eds.), Socialnay Psyhologia [Social Psychology] (pp. 85-113). Moscow: Nauka.

Kugler, K., \& Jones, W. H. (1992). On conceptualizing and assessing guilt. Journal of Personality and Social Psychology, 62, 318-327. doi: 10.1037/0022-3514.62.2.318

Kulchitskaya, E. I. (1966). K probleme nravstvennogo razvitiya rebenka (razvitie chuvstva styda u detey doshkolnogo vozrasta) [The problem of moral development (development of a sense of shame in preschool children)]. Voprosy Psyhologii [Issues of Psychology], 1, 116-124.

Lewis, H. B. (1971). Shame and guilt in neurosis. New York: International Universities Press.

Makogon, I. K., \& Enikilopov, S. N. (2009). Moralnye emocii i regulyciy povedeniya [Moral emotions and behavior regulation]. Nauka i Obrazovanie [Science and Education], 8, 34-38.

Nathanson, D. L. (1992). Shame and pride: Affect, sex, and the birth of self. New York: Norton.

Potter-Efron, R. T. (2002). Styd, vina i alkogolism: Klinicheskay practika [Shame, guilt and alcoholism: Clinical practice]. Moscow: Institut Obschegumanitarnyh Issledovaniy.

Schmader, T., \& Lickel, B. (2006). The approach and avoidance function of guilt and shame emotions: Comparing reactions to self-caused and other-caused wrongdoing. Motivation and Emotion, 30, 42-55. doi: 10.1007/s11031-006-9006-0

Tangney, J. P. (1996). Conceptual and methodological issues in the assessment of shame and guilt. Behaviour Research and Therapy, 34(9), 741-754. doi: 10.1016/0005-7967(96)00034-4

Tangney, J. P., \& Dearing, R. L. (2002). Shame and guilt. New York: Guilford Press.

Tangney, J. P., Dearing, R. L., Wagner, P. E., \& Gramzow, R. H. (2000). The Test of Self-Conscious Affect-3 (TOSCA-3). Fairfax, VA: George Mason University.

Tangney, J. P., Stuewig, J., \& Mashek, D. J. (2007). Moral emotions and moral behavior. In Annual Review of Psychology (pp. 345-363). Los Angeles: University of California - Los Angeles. 
Tangney, J. P., Wagner, P., \& Gramzow, R. (1989). The Test of Self-Conscious Affect. Fairfax, VA: George Mason University.

Tracy, J. L., \& Robins, R. W. (2004). Putting the self into self-conscious emotions: A theoretical model. Psychological Inquiry, 15, 103-125. doi: 10.1207/s15327965pli1502_01

Wolf, S. T., Cohen, T. R., Panter, A. T., \& Insko, C. A. (2010). Shame proneness and guilt proneness: Toward the further understanding of reactions to public and private transgressions. Self \& Identity, 9, 337-362. doi: 10.1080/15298860903106843

Received: 06 September 2013

Accepted: 15 November 2013

Available online: 15 December 2013 